\title{
FAKTOR-FAKTOR YANG MEMPENGARUHI PERSEPSI KOMISI PENILAI AMDAL STUDI KASUS PROVINSI SULAWESI UTARA
}

\author{
Dena Natalia Langi ${ }^{1 *}$, Qomariyatus Sholihah ${ }^{2)}$, Rita Parmawati ${ }^{2) 3)}$ \\ ${ }^{1)}$ Magister Pengelolaan Sumberdaya Lingkungan dan Pembangunan, Pascasarjana, \\ Universitas Brawijaya, Malang \\ ${ }^{2)}$ Pascasarjana, Universitas Brawijaya, Malang \\ ${ }^{3 *}$ Jurusan Sosial Ekonomi, Fakultas Pertanian, Universitas Brawijaya, Malang \\ *Email: rita_parmawati@ub.ac.id
}

\section{ABSTRAC \\ FACTOR AFFECTING PERCEPTION OF EIA ASSESMENT TEAM CASE STUDY IN NORTH SULAWESI PROVINCE}

EIA is part of several instruments to prevent pollution and environmental damage, and in order to improve its quality and effectiveness, EIA document will be assessed by the EIA Assessment Commission depending on its authority. The assessment ability of the EIA Assessment Commission is also influenced by perceptions, so it is necessary to analyze the influence of internal and external factors on the perception of the EIA Assessment Commission in North Sulawesi, so it can provide good suggestions and input for better regional development and towards environmental sustainability. The research sample were 57 respondents and then used in-depth interviews guided by the questionnaire to digging information. The data obtained were then analyzed using Partial Least Square (PLS) to observe the impact of internal and external factors on the perception of the EIA Assessment Commission. Internal factors including age, education level, and family responsibilities do not significantly affect the level of perception, while internal factors such as experience and integrity as well as all external factors have a significant effect on perception. Work experience has a strong impact on the perception of the EIA Assessment Commission to always support the environmental conservation movement and integrity have an impact on the emergence of rational and fair decision making

Key words: EIA, Integrity, Assessment, Perception.

\section{PENDAHULUAN}

Lingkungan hidup yang terjaga termasuk ke dalam hak asasi manusia, hal ini telah tercantum pada Undang-Undang Dasar 1945. Pemerintah bersama dengan masyarakat wajib melindungi lingkungan dan melakukan pengelolaan yang berkelanjutan untuk mencapai cita-cita bangsa. Hal ini terwujud dengan adanya kebijakan-kebijakan pemerintah yang bertujuan untuk pengelolaan dan perlindungan lingkungan yang baik. Setelah Undang-Undang Dasar 1945, pemerintah menitikberatkan pembahasan lingkungan pada Undang-Undang Nomor 32 Tahun 2009 tentang Perlindungan dan Pengelolaan Ligkungan Hidup. Pada undang-undang ini, salah satu instrumen perlindungan lingkungan adalah AMDAL atau Analisis Mengenai Dampak Lingkungan. AMDAL adalah instrumen yang digunakan untuk menentukan dampak proyek dan program yang diusulkan terhadap aspek lingkungan, 
termasuk dimensi manusia di sekitarnya. Hasil dari penyusunan AMDAL yang sistematis ini nantinya dapat digunakan oleh pemerintah dan pengambil keputusan lainnya dalam menilai apakah akan berinvestasi, melaksanakan, atau mengizinkan proyek yang diusulkan seperti tambang, waduk, jalan raya, dan pertanian (Barret, 2007; King, 2008). Di Indonesia, keberadaan AMDAL sangat penting sebagai salah satu kunci pengambilan keputusan dalam penerbitan izin lingkungan terkait dengan kegiatan atau usaha (Ciptaningrum dkk. 2017)

Tujuan dari AMDAL adalah mengumpulkan data secara sistematis, obyektif, ilmiah dan komprehensif, menganalisis informasi, memprediksi dan menilai potensi dampak lingkungan dari suatu pembangunan yang diusulkan. Proses AMDAL harus transparan, masuk akal dan memungkinkan organisasi terkait, kelompok, penduduk lokal dan pemangku kepentingan lainnya untuk berpartisipasi dan memberikan pendapat (Jou \& Liaw, 2006). Sehingga AMDAL biasanya disusun sebelum pelaksanaan kegiatan atau pada tahap perencanaan dengan tujuan memberikan bahan pertimbangan terkait konsekuensi yang mungkin terjadi dan sebagai langkah mewujudkan pembangunan yang berwawasan lingkungah untuk mencapai pembangunan berkelanjutan (Terri, 2018; Barrett, 2007).

Berdasarkan penjelasan Hakim (1992), kualitas dan keefektifan dari penerapan AMDAL akan dipengaruhi oleh institusi dan prosedur kerja. Salah satu proses dalam prosedur kerja AMDAL yaitu penilaian dokumen oleh Komisi Penilai AMDAL (KPA) yang terdiri dari penilaian Kerangka Acuan (KA), ANDAL, dan RKL RPL (Taufiq, 2011). KPA memiliki kewenangan dalam proses pemeriksaan mulai dari tahap administrasi hingga tahap uji kelayakan dari dokumen AMDAL dengan tujuan menyempurnakan dan menyelaraskan dokumen AMDAL agar sesuai dengan Peraturan Menteri Lignkungan Hidup Nomor 16 Tahun 2012 tentang Pedoman Penyusunan Dokumen Lingkungan Hidup. Sehingga nantinya dapat terbentuk dokumen AMDAL yang berkualitas dan sesuai dengan prinsip pembangunan berkelanjutan.

KPA dalam pelaksanaaan tugasnya, memiliki kewajiban memberikan saran, pendapat, dan pertimbangan sebagai dasar pengambilan keputusan dalam menentukan Kelayakan Lingkungan dari kegiatan yang dilakukan berdasarkan pada rencana pembagian wilayah dan tata ruang wilayah. Sehingga kunci keberhasilan Komisi penilai AMDAL dalam penilaian dokumen lingkungan diperlukan sumber daya manusia yang mengetahui dan memahami proses penilaian yang berdasarkan aturan perundang undangan di bidang pengelolaan lingkungan serta adanya dukungan partisipasi dari semua unsur yang ada di dalam komisi penilai AMDAL. Mengacu pada berbagai tugas dari anggota komisi penilai AMDAL maka kemampuan secara teknis dan obyektifitas dituntut dari setiap anggota KPA dalam proses penilaian. Namun pada kenyataanya pada proses penilaian, wakil dari unsur-unsur dalam anggota KPA yang hadir dalam penilaian dokumen AMDAL kurang memahami terkait tugas dan tanggung jawab sebagai anggota komisi penilai AMDAL karena memiliki persepsi yang seringkali berbeda hingga mempengaruhi tingkat partisipasi. Hal ini membuat persepsi dari masing-masing individu pada Tim KPA menjadi hal yang penting dan mendasar.

Persepsi adalah proses untuk mengelola dan menafsirkan informasi yang dirasakan oleh indera manusia dalam rangka memberikan makna kepada lingkungan di sekitarnya. Persepsi merupakan wujud pribadi bagaimana 
seseorang memandang dunia yang diwarnai oleh berbagai elemen sosiokultural. Penelitian dari Markus dan Kitayama (1991) menunjukkan bahwa individu dengan budaya yang berbeda memiliki persepsi yang sangat berbeda tentang individu lain di sekitarnya. Perbedaan ini dapat dilihat saat membandingkan dua budaya yang berbeda. Sifat pengalaman individu juga dapat dipengaruhi ketika dua budaya bertemu. Persepsi nyeri saat melahirkan ditemukan meningkat ketika etnis wanita yang bersalin berbeda dengan etnis dominan penolong (Olayemi, dkk., 2009). Selain itu persepsi seseorang juga akan mempengaruhi perilakunya di saat ini atau masa depan (behavior). Pengambilan keputusan menjadi salah satu hal yang dipengaruhi oleh persepsi dan perilaku individu (Fabra-Crespo, 2014). Sehingga tujuan dari penelitian ini adalah menganalisis pengaruh dari faktor internal dan eksternal terhadap persepsi dari Komisi Penilai AMDAL di Sulawesi Utara, sehingga dalam prosesnya dapat memberikan saran dan masukan yang baik demi perkembangan daerah dan kelestarian lingkungan.

\section{METODOLOGI}

Penelitian ini menggunakan dua pendekatan yaitu eksplanasi (explanatory research) yang dikombinasikan dengan dengan deskriptif (descriptive research). Penelitian ini dilakukan pada bulan Oktober hingga November 2020. Sumber data terdiri dari data primer dan data sekunder. Responden dalam penelitian ini berjumlah 47 responden yang terdiri dari Tim Komisi Penilai yang berasal dari beberapa instansi, Perwakilan dari Sekretariat Komisi Penilai AMDAL, perwakilan dari Tim Teknis Komisi Penilai AMDAL, dan responden yang pernah mengikuti rapat penilaian dokumen lingkungan, kemudian dilakukan wawancara mendalan (indepth interview) untuk memperoleh data primer. Sedangkan data sekunder didapatkan dari data-data KPA yang berada di Dinas Lingkungan Hidup Kabupaten dan Provinsi.

Variabel dalam penelitian ini yaitu Faktor internal meliputi umur, tanggungan keluarga, pendidikan, pengalaman, integritas dan Faktor eksternal yang tersusun dari ketersediaan informasi, ketersediaan sarana, ketersediaan anggaran, adanya pelatihan, dan dukungan kebijakan. Untuk variabel terikatnya adalah persepsi Komisi Penilai AMDAL Provinsi Sulawesi Utara. Kemudian dianalisis dengan Partial Least Square (PLS), metode analisis ini tergolong akurat karena penerapannya dapat digunakan pada semua skala data, ukuran sampel tidak harus besar dan juga tidak membutuhkan banyak asumsi, tetapi jumlah sampel yang besar akan lebih mampu meningkatkan presisi estimasi (Henseler dkk, 2014; Ghozali, 2014).

\section{HASIL DAN PEMBAHASAN}

Ada banyak faktor internal dan eksternal yang mempengaruhi cara kita memandang dunia di sekitar kita. Faktorfaktor yang mempengaruhi persepsi kita adalah penginderaan, target dan situasi. Budaya dan perbedaan individu kita memainkan peran yang sama dalam persepsi seseorang. Berdasarkan penelitian dari Arifin, dkk. (2017), faktor internal dan ekternal dalam diri seseorang akan berpengaruh secara signifikan terhadap gaya berpikir, cara pandang, dan juga persepsi dari individu. Beberapa faktor internal yang berpengaruh terhadap persepsi adalah umur individu (Bertolino, dkk, 2013; Osmani, 2016), tingkat pendidikan (Putra, 2018), pengalaman (Samner dan Samuel, 2009), kebutuhan, dan penilaian. Faktor eksternal seperti 
keadaan lingkungan, cara memperoleh informasi, dan stimulus luar lainnya (Toha, 2003; Prasetijo, 2005). Dalam penelitian ini faktor yang dianalisis untuk dapat mengetahui tingkat persesi dari Komisi Penilai AMDAL juga dibedakan menjadi faktor internal (umur, tanggungan keluarga, pendidikan, pengalaman, dan integritas) dan eksternal (ketersediaan informasi, ketersediaan sarana, ketersediaan anggaran, adanya pelatihan, dan dukungan kebijakan). Kategori yang terdapat pada faktor intenal dan eksternal yang telah diobservasi, kemudian dianalisis dengan menggunakan Partial Least Square (PLS). PLS digunakan untuk mengetahui pengaruh dari masing-masing variabel terikat yang meliputi Umur (X1), Tingkat Pendidikan (X2), Tanggungan Keluarga (X3), Pengalaman Bekerja (X4), Integritas (X5), Ketersediaan Informasi (X6), Ketersediaan Sarana (X7), Ketersediaan Anggaran (X8), Pelatihan (X9), dan Dukungan Kebijakan (X9) dengan Persepsi Tim Komisi Penilai AMDAL (Y) (Tabel 1).

Tabel 1. Hasil Partial Least Square (PLS)

\begin{tabular}{|c|c|c|c|c|c|c|}
\hline FAKTOR & $\begin{array}{l}\text { ORIGINAL } \\
\text { SAMPLE } \\
(0) \\
\end{array}$ & $\begin{array}{c}\text { SAMPLE } \\
\text { MEAN (M) }\end{array}$ & $\begin{array}{c}\text { STANDARD } \\
\text { DEVIATION } \\
\text { (STDEV) }\end{array}$ & $\begin{array}{l}\text { T } \\
\text { STATISTICS } \\
(\mid \text { O/STDEV } \mid) \\
\end{array}$ & $\begin{array}{c}\text { P } \\
\text { VALUES }\end{array}$ & KETERANGAN \\
\hline \multicolumn{7}{|c|}{ FAKTOR INTERNAL } \\
\hline Umur & -0.048 & -0.022 & 0.163 & 0.296 & 0.383 & $\begin{array}{l}\text { TIDAK } \\
\text { SIGNIFIKAN }\end{array}$ \\
\hline Tingkat Pendidikan & -0.028 & -0.034 & 0.12 & 0.234 & 0.408 & $\begin{array}{l}\text { TIDAK } \\
\text { SIGNIFIKAN }\end{array}$ \\
\hline $\begin{array}{l}\text { Tanggungan } \\
\text { Keluarga }\end{array}$ & 0.004 & 0.029 & 0.124 & 0.034 & 0.487 & $\begin{array}{l}\text { TIDAK } \\
\text { SIGNIFIKAN }\end{array}$ \\
\hline $\begin{array}{l}\text { Pengalaman } \\
\text { Bekerja }\end{array}$ & 0.344 & 0.303 & 0.187 & 1.838 & 0.033 & SIGNIFIKAN \\
\hline Integritas & 0.344 & 0.359 & 0.151 & 2.27 & 0.012 & SIGNIFIKAN \\
\hline \multicolumn{7}{|c|}{ FAKTOR EKSTERNAL } \\
\hline $\begin{array}{l}\text { Dukungan } \\
\text { Kebijakan } \\
\end{array}$ & -0.191 & -0.243 & 0.102 & 1.868 & 0.031 & SIGNIFIKAN \\
\hline Pelatihan & -0.309 & -0.284 & 0.164 & 1.884 & 0.03 & SIGNIFIKAN \\
\hline $\begin{array}{l}\text { Ketersediaan } \\
\text { Anggaran }\end{array}$ & 0.367 & 0.309 & 0.198 & 1.856 & 0.032 & SIGNIFIKAN \\
\hline $\begin{array}{l}\text { Ketersediaan } \\
\text { Sarana }\end{array}$ & 0.394 & 0.317 & 0.21 & 1.877 & 0.031 & SIGNIFIKAN \\
\hline $\begin{array}{l}\text { Ketersediaan } \\
\text { Informasi } \\
\end{array}$ & -0.308 & -0.272 & 0.172 & 1.786 & 0.037 & SIGNIFIKAN \\
\hline
\end{tabular}

Tabel 1, menunjukkan faktor internal seperti umur, tingkat pendidikan, dan tanggungan keluarga memiliki pengaruh positif tidak signifikan terhadap persepsi dari Komisi Penilai AMDAL. Umur dan tingkat pendidikan berkaitan dengan kematangan dalam berpikir, tetapi umur sendiri memiliki hubungan yang negatif terhadap kinerja dalam pekerjaan (Joseph, 2014). Selain itu, Gartska, dkk. (2004) dan Sproten, dkk. (2018) juga menyebutkan bahwa perbedaan umur tidak dapat menunjukkan kemampuan seseorang dalam mengambil risiko-risiko pilihan yang ada. Sehingga persepsi dari Komisi Penilai AMDAL dalam menilai dokumen lingkungan tidak serta merta melibatkan faktor-faktor internal seperti umur, tingkat pendidikan, dan tanggungan keluarga karena masih banyak faktor lain yang akan berpengaruh signifikan terhadap persepsi Komisi Penilai AMDAL.

Variabel-variabel yang berpengaruh secara signifikan terhadap persepsi 
Komisi Penilai AMDAL antara lain adalah pengalaman bekerja, integritas, dukungan kebijakan, pelatihan, ketersediaan anggaran, ketersediaan sarana, dan ketersediaan informasi. Pengalaman bekerja akan berkaitan dengan kemampuan Komisi Penilai AMDAL dalam menjadi pemecah masalah (problem solver), karena dengan pengalaman yang sudah banyak membuat cara berpikir dan cara pandang menjadi lebih luas. Pengalaman bekerja sebagai penilai sangat mempengaruhi persepsi terhadap penilaian dokumen lingkungan. Keikutsertaan dalam rapat-rapat penilaian membentuk persepsi yang kuat terkait pentingnya pelestarian lingkungan dalam penilaian dokumen AMDAL dan semakin mengerti menilai terkait keadaan lingkungan di lokasi kegiatan yang direncanakan dan dapat memitigasi dampak penting dari suatu usaha/kegiatan. Hal ini berarti untuk membentuk persepsi yang baik dalam penilaian dokumen AMDAL diperlukan pengalaman bekerja seorang penilai. Integritas adalah sifat yang digambarkan sebagai kewibawaan dan kejujuran. Komisi Penilai AMDAL diwajibkan untuk memiliki sifat jujur, karena setiap keputusan yang dikeluarkan memiliki kemungkinan untuk berdampak langsung pada stabilitas lingkungan pada rencana kegiatan yang akan terjadi. Jika Komisi Penilai AMDAL tidak memiliki integritas maka kerusakan lingkungan tidak dapat dielakkan. Tingkat Integritas mengindikasikan bahwa penilai sudah memiliki sikap jujur dan menghargai perbedaan pendapat serta berlaku adil dan menolak adanya kecurangan prinsip (Sunarto, 2003). Menurut Landeng (2017), penilaian yang dilakukan pada dokumen AMDAL menuntut sikap yang professional, akuntabel, dan berintegritas agar instrumen yang ada dapat dimanfaatkan sebagai dasar dalam pengambilan kepurusan yang transparan, efektif, dan efisien, karena termasuk langkah penting dalam mendapatkan Izin Lingkungan. Hal ini mendukung pernyataan dari Wahyono (2012) bahwa tingkat integritas dapat ditentukan berdasarkan persepsi yang benar.

Ketersediaan informasi berkaitan dengan ketersediaan SOP dalam proses penilaian dokumen AMDAL dan informasi yang tersedia tentang deskripsi kegiatan dalam dokumen AMDAL. Ketersediaan SOP proses penilaian Dokemen AMDAL pada Komisi Penilai AMDAL Provinsi Sulawesi Utara dalam bentuk leaflet yang disediakan di sekretariat komisi yang bisa didapatkan dengan mudah baik oleh pemrakarsa maupun Komisi Penilai dan SOP yang dituangkan pada papan informasi yang diletakkan pada pintu masuk sekretariat. Ketersediaan sarana terkait ruangan sekretariat dan ruangan rapat komisi untuk penyelenggaraan rapat penilaian dokumen AMDAL juga cukup baik kerena ruang rapat penilaian pada Komisi Penilai AMDAL yang berada di Dinas Lingkungan Hidup dilengkapi dengan peralatan yang sangat memadai yang mampu memfasilitasi penyelenggaraan rapat penilaian. Namun untuk ketersediaan sarana perpustakaan atau tempat menyimpan dokumen di sekretariat Komisi Penilai AMDAL masih dianggap kurang dan cukup oleh responden, hal ini disebabkan karena ruangan penyimpanan yang kurang luas yang tidak mampu menampung dokumen lingkungan yang ada atau melebihi kapasitas penyimpanan dokumen sehingga kurang maksimal dalam penyimpanan dokumen. Ketersediaan anggaran juga berpengaruh signifikan karena ini berkaitan dengan honorarium, penggandaan dokumen AMDAL, biaya penyelenggaraan rapat, transport lokal, akomodasi, dan uang harian dengan standar biaya yang ditetapkan oleh pemerintah. Sekretariat komisi di Provinsi Sulawesi Utara mengatur setiap kegiatan dan jasa 
penilaian yang disediakan oleh pemrakarsa dan dikelola secara transparan sesuai dengan standar biaya umum dari pemerintah Provinsi Sulawesi Utara.

Pelatihan terkait dengan penilaian AMDAL juga berpengaruh secara signifikan, karena pelatihan akan berdampak pada peningkatan kemampuan-kemampuan berpikir dan peningkatan kapasistas komisi penilai AMDAL terkait tata laksana penilaian AMDAL. Sehingga diharapkan adanya peningkatan kapasitas dari komisi penilai terkait tata laksana penilaian dan pemeriksaan dokumen lingkungan berupa Bimbingan teknis, sosialisasi maupun seminar yang menunjang kegiatan penilaian dokumen AMDAL. Pelatihan dalam bentuk bimbingan teknis setiap tahunnya dilaksanakan oleh Dinas Lingkungan Hidup Provinsi Sulawesi Utara. Namun, karena keterbatasan anggaran dari pihak penyelenggara maka jumlah peserta dibatasi sesuai dengan jumlah anggaran pada DPA Dinas Lingkungan Hidup Provinsi Sulawesi Utara, hingga belum bisa mengakomodir seluruh Komisi Penilai yang ada, baik di kabupaten atau kota maupun di tingkat Provinsi. Dukungan kebijakan dari Provinsi Sulawesi Utara juga berpengaruh secara signifikan terhadap persepsi Komisi Penilai AMDAL. Karena kebijakan pemerintah daerah berkaitan langsung dengan visi dan misi daerah dan berkaitan dengan pertimbangan yang akan muncul dalam proses penilaian dokumen lingkungan. Provinsi Sulawesi Utara juga mendukung kelestarian dan keseimbangan lingkungan yang dapat dilihat melalui terbitnya produk hukum berupa peraturan daerah untuk menunjang proses perizinan lingkungan yang di dalamnya terkait dengan penilaian dokumen AMDAL, yang salah satunya adalah dengan adanya pendelegasian penandatanganan izin lingkungan dari Gubernur kepada Kepala
PTSP untuk mempermudah dan mempercepat proses birokrasi.

\section{SIMPULAN DAN SARAN}

Faktor internal yang tergolong berpengaruh positif signifikan terhadap persepsi penilai adalah pengalaman bekerja karena dapat berdampak pada persepsi kuat dari Komisi Penilai AMDAL untuk selalu mendukung gerakan konservasi lingkungan dan integritas dapat berdampak pada timbulnya pengambilan keputusan yang rasional dan adil. Sedangkan faktor lain yaitu umur, tanggungan keluarga dan pendidikan tidak signifikan karena ketiga faktor tersebut tidak cukup berdampak langsung pada proses pengambilan keputusan dan kelayakan bekerja. Sedangkan faktor eksternal berpengaruh secara signifikan terhadap persepsi dan kapasitas dari Komisi Penilai AMDAL. Provinsi Sulawesi Utara perlu memperhatikan variabel-variabel yang berpengaruh secara signifikan ini, utamanya pada faktor pengalaman dan integritas, karena kedua faktor ini dapat memberikan dampak yang besar pada pengambilan keputusan secara individu dalam menilai dokumen lingkungan kegiatan.

\section{DAFTAR PUSTAKA}

Arifin, H.S., Fuady, I., Kuswarno, E. 2017. Analisis Faktor yang Mempengaruhi Persepsi Mahasiswa Untirta Terhadap Keberadaan Perda Syariah di Kota Serang. Jurnal Penelitian Komunikasi dan Opini Publik, 21(1): 88-101.

Hakim, A. 1992. Pendayagunaan Hukum dalam Pencegahan Pencemaran Lingkungan Akibat Limbah Industri di Kota Surabaya. LIPI. Jakarta.

Barret, B. 2007. Environmental Impact Assessment Course Module UN 
University. Department of Global, Urban and Social Studies UNU Academic Programme Officer. UK.

Bertolino, M., Truxillom D.M., dan Fraccaroli, F. 2012. Age Effects Perceived Personality and Job Performance. Journal of Managerial Psychology, 28(7/8): 867-885.

Ciptaningrum, Y.I., Atikah, W., dan Fadhilah, N.L. 2017. Peran Serta Masyarakat dalam Proses Penyusunan Analisis Mengenai Dampak Lingkungan Hidup. EJournal Lentera Hukum, 4(1): 6178.

Fabra-Crespo M., Saastamoinen O., Matero J., dan Mäntyranta H. 2014. Perceptions and realities: public opinion on forests and forestry in Finland, 1993-2012. Silva Fennica, 48(5)

Garstka, T.A., Schmitt, M.T., Branscombe, N.R., dan Hummert, M.L. 2004. How Young and Older Adults Differ in Their Responses to Perceived Age Discrimination. Psychology and Aging, 19(2): 326335.

Ghozali, I. 2014 Structural Equation Modelling: metode alternative dengan Partial Least Square (PLS). Semarang: Badan Penerbit Universitas Diponegoro.

Henseler, J., Dijkstra, T.K., Sarstedt, M., Ringle, C.M., Diamantopoulos, A., Straub, D.W., Ketchen, D.J., Hair, J.F., Hult, G.T.M., dan Calantone, R.J. 2014. Common Beliefs and Reality About PLS: Comments on Ro“nkko. and Evermann. Organizational Reseacrh Methods, 17(2): 182-209.

Joseph, D. 2014. Age Diversity and Its Impact on Employee Performance in Singapore. International Journal of Research \& Development, 21(5): 80-98
Jou, J., dan Liaw, S. 2006. A Study on Establishment of EIA System in the Taiwan Region. Journal of Environmental Assessment Policy and Management, 8(4): 479-494.

King, T.F. 2008. Environmental Impact Assessment and the Law. USA: Academic Press.

Landeng, A.A. 2017. Peranan Analisis Mengenai Dampak Lingkungan Dalam Perlindungan Dan Pengelolaan Lingkungan Hidup Berdasarkan Peraturan Pemerintah Nomor. 27 Tahun 2012 Tentang Izin Lingkungan. LEX PRIVATUM, 5(6): 91-99

Markus, H.R. dan Kitayama, S. 1991. Culture and the self: Implications for cognition, emotion, and motivation. Psychological Review, 98(2): 224-253.

Olayemi, O., Morhason-Bello, I. O., Adedokun, B. O., dan Ojengbede, O. A. 2009. The role of ethnicity on pain perception in labor among parturients at the university college hospital Ibadan. Journal of Obstetrics \& Gynaecology Research, 35(2): 277-281.

Osmani, J. 2016. The Impact of Age on the Perception of Cognitive Abilities and Decision-Making Skills. European Journal of Social Sciences, 3(4): 114-125.

Putra, A.P. 2018. Pengaruh Tingkat Pendidikan \& Persepsi Terhadap Partisipasi Masyarakat Dalam Pengelolaan Daya Tarik Wisata Air Terjun Selendang Arum, Songgon, Banyuwangi. JUMPA, 5(1): 171-192

Sproten, A., Diener, C., Fiebach, C., dan Schwieren, C. 2018. Decision making and age: Factors influencing decision making under uncertainty. Journal of Behavioral and Experimental Economics, 76 
Sumner, M., dan Samuel, A. G. 2009. The effect of experience on the perception and representation of dialect variants. Journal of Memory and Language, 60(4): 487-501.

Taufiq, M. 2011. Kedudukan \& Prosedur AMDAL dalam Pengelolaan Lingkungan Hidup. Jurnal WIGA, 2(2): 21-42.
Terri, S. 2018. Importance of an EIA in Environmental Protection. USA: Virginia Department of Environmental Quality.

Wahyono, A dan Wardiat, D. 2012. Integritas Pelayanan Publik Dalam Perizinan Pemanfaatan Air Bawah Tanah Di Dki Jakarta. Jurnal Masyarakat dan Budaya, 14(1): 99-12 